\title{
2 What Do We Revitalise?
}

\section{Julia Sallabank and Jeanette King}

\section{Introduction}

The question 'what do we revitalise' may seem a rather unusual one. After all, isn't the answer obvious? We want to revitalise our language. But in order to do so, we need to think about the kinds of questions that are tackled in Chapter 1, such as who wants to 'save' the language, and for what purposes?

For example, do we want to expand the scope of the language to be able to use it in schools, or to talk about new technology? That might require new terminology: in which case, who should decide on it, and how? Should we try to recover 'traditional' language, or should we try to re-invent our language for a new generation - or something in between? If there is a range of varieties of our language, should we focus on just one? Should we try to create a standard language (copying majority languages), or support linguistic diversity in its fullest sense? Such questions are more often related to political struggles and ideological debates about language ownership or authenticity (see Chapter 7) - and there may be bitter arguments about what the 'correct' form of a word or expression is. If a language is highly endangered, it may only be used infrequently and in a fragmented way, so it may need to be reconstructed.

In Chapter 6, Justyna Olko and José Antonio Flores Farfán discuss the varied range of people who may be involved in language revitalisation; we need to consider all their diverse needs and wishes when planning what to revitalise. An endangered language community consists not only of people who speak the language; it includes others who have an interest in what is to be revitalised, and whose views need to be taken into account. For example, people who would like to claim an association with the language by learning it or by supporting revitalisation efforts (e.g. by helping to develop an app) may have other ideas on what to revitalise than people who grew up speaking the language but have lost their fluency through many years of disuse. Members of the wider community also have a stake in policies directed at language (even if only through paying taxes that fund public policy measures). 
In broad terms, there is frequently a distinction between traditional speakers and new speakers, whose views on what to focus on and how may diverge significantly. Diplomacy may be needed to reconcile all points of view; one possible way of handling conflicting agendas is to see a range of activities as complementary parts of an overall plan, rather than mutually exclusive.

We also need to remember that decisions we make now will affect how the language is used in the future - not just how it is used now. Do we want to focus on specific areas of use, or look at language revitalisation in a more holistic way? It is important not to limit future options by restricting language to particular areas of life; even if we don't use all the variations or topics now, we should ensure that there is a safe record of all the rich diversity of a language. But we also need to bear in mind that language revitalisation is not only, or always, just about language, as we discuss later and in Chapters 1 and 9.

There are many different types of languages. While we typically think of language as being oral, or spoken, other means can be employed to convey information, such as sign languages and whistling languages. Whatever type, people try to revitalise languages because they are regarded as being endangered, and because they feel an emotional link to that language. All types of endangered languages have both similarities and differences in why they are endangered and how we go about reversing this, so it is important both to look at our own contexts and to learn from what others have tried (see Chapter 12 on links with other groups).

\section{Contexts of Use}

Every language variety has a number of forms; that is, the ways language is used will change according to who is using it, when, where, and for what purpose. For example, the language used to interact with children will differ from that used in formal contexts. This is not just a matter of using alternative words; there will also be differences in the ways sentences are constructed. Languages aren't single, unchanging entities; because they are used in a wide range of forms by a wide range of people in various places for distinct purposes, they naturally change and evolve. There are often debates in language revitalisation movements about how much change is desirable; this is discussed more in 'Language Change' below.

The task of revitalisation can seem overwhelming when viewed in its entirety, so some prioritisation may be necessary (see Chapter 4 on planning). Assessing what resources are available, and to what extent your language is still spoken or not, will help you decide where and how you want to concentrate your revitalisation efforts. Settings where language is 
used include the home, school, the workplace, social media, religion, bureaucracy, political life, sports commentary, etc. Some of these require specific types of vocabulary or levels of formality (called registers); often minority languages don't have, or have lost, forms of language that are needed for particular settings or registers. Critics of language revitalisation may claim that this is proof that the language is inferior and not capable of being used in all areas of (especially modern) life. For this reason many language supporters want to expand the spaces in which their language is used. Language promoters may focus on useful or practically oriented areas such as grammar terminology for teaching; others may focus on high-status areas to increase the language's prestige.

Language revitalisation often focuses on transmitting language to children; the home and school are therefore key spaces of use. We need to be aware that there is a particular kind of language in those situations, that of adult-child interactions. In Guernsey, where most fluent speakers of Guernesiais are now aged over 80, Julia Sallabank has been involved in trying to collect examples of adult-child interaction, as well as children's rhymes and games, from older speakers. This has proved difficult, as there are now very few people alive who have experience of raising their children in Guernesiais. So this may be a way of using language that has to be reconstructed. Where there are still children learning the language (or people who remember raising children in the language), it is important to record this type of language.

One effective and widely used and respected revitalisation method is to implement preschool language immersion centres. These were pioneered in 1982 in New Zealand with the Māori language. The idea behind these centres is to transmit the language directly from an older generation of speakers to a new generation of child speakers. However, if the older speakers are few in number and quite elderly, this option needs to be thought out carefully. To begin with, not all older people have the stamina and desire to interact with preschoolers for many hours a day. In addition, older speakers need to understand that their role is to speak the target language, and only the target language, with the children. That is, it is not necessary or desirable to sit the children down and overtly 'teach' the language. The type of language used with small children is usually quite basic, often consisting of descriptions and commands. But as the children grow and get older, a more sophisticated repertoire is required. Ideally, if possible, children should also be exposed to adult interactions in the language. Everyday interactions between adults such as greetings, apologies, requests, etc. are often surprisingly lacking from linguists' records, but they are important if you want to use your language for conversation and social activities. In Wales, some parents have noticed that children from 
English-speaking families who go to Welsh-medium school are quite direct in their speech: they have been taught simple commands, but not polite forms of language, which are often more complicated grammatically. However, they can be taught as 'chunks' of language whose grammar does not need to be analysed by the children at this stage.

While developing new uses and new words for a language, it is important not to forget traditional areas of life, especially home, socialising, and child language (including games, nursery rhymes, etc.). When schools take over the role of passing on the language, children might only learn school language, and not know how to make friends and be intimate in their language. As a result, they may not speak the language outside school, or with their own children in due course (as has been found in Wales after thirty years of immersion teaching). It has also been found in Brittany that children who learn a formalised Breton at school are unable to converse with older speakers who use regional varieties and more informal speech.

Most language use outside basic conversation involves reading and writing. If the language you are working with is not written, creating an agreed writing system is an essential area to tackle. This will be dealt with in Chapter 14.

\section{Variation and Standardisation}

It is not uncommon for one variety of a language to be quite vibrant but for other varieties to be under threat. Minority varieties are particularly vulnerable because they are often regarded as being of lesser value than the dominant or 'standard' variety, which has more status. Even speakers can believe that their way of speaking is not as important or valid as more prestigious variants. In Jersey, regional varieties of the island language Jèrriais are called accents. Some accents are disappearing because language teaching focuses on one accent, which has been formalised with a standard spelling that doesn't always take into account other accents. The formalised accent/variety used in schools is seen by some as the 'correct' variety.

Many people get involved in language revitalisation because they want to reconnect with their roots. They want to learn the variety that they identify with; for them learning another version would not fulfill that requirement. For example, most speakers of Māori live in the North Island of New Zealand, but the Kāi Tahu iwi (tribe) in the South Island are working to increase the numbers of speakers of their local variety.

In many cases, an endangered or minority language is perceived as 'only a dialect' - or designated as a dialect by the national government. This may have little to do with the degree of linguistic difference, but more to do with status and identity. In this book, we prefer to use the word 'varieties' when 
we talk about how ways of speaking differ across regions, age groups, etc. This is because the term 'dialect' has negative connotations of 'incorrect' and 'low status', and is often used to denigrate minority languages. Language activists often campaign to have the linguistic variety that they identify with recognised as a language in its own right. These issues are discussed in more depth in Chapter 11 on policy and Chapter 7 on ideologies.

There is often pressure to create, teach, and learn a standard version of an endangered language. In the process of standardisation of national languages, the standard is usually based on the variety used by an urban intelligentsia. However, urban varieties of endangered languages typically disappear at an early stage, leaving the choice of prestige variety unclear. Minority and endangered languages usually have extensive variation, and there is often no obvious prestige or standard variety, which can lead to disagreements. In many cases there is no tradition of written literature, or authors may write in a wide range of styles, varieties and spellings, or even different types of script.

It is often assumed that endangered languages have to copy the model of national languages, which have a standard 'correct' way of writing and speaking, especially if we want to teach our languages in schools. But this can lead to local ways of speaking being minoritised again. Some language supporters argue that it is better to prioritise more widely used varieties. But there are other models, such as in Corsica, where different varieties are recognised as equally important, and learners are given a choice of which they want to identify with.

\section{What Is It For?}

Often when we talk about language revitalisation, our ultimate aim is for the language to be used again by a range of community members from young to old. (This may be the long-term, ultimate aim, but there are many steps to be taken before you can reach it - see Chapter 2 on planning.) Being aware of what resources are available puts us in a better position to know what sort of language revitalisation is possible and achievable and for what purposes. Without considering this we run the risk of activities that fail due to lack of planning. The important thing to remember is that there is no right or wrong when deciding what aspects of your language you focus on. It is also important to ensure that what you focus on now does not limit future options.

But full community use is not the only form of language revitalisation. Your language may have very few, if any, remaining speakers. Such contexts are termed post-vernacular: that is, the language is no longer used 
as a vernacular, for everyday purposes. However, even in these situations there are productive things that can be done. In the USA, the Breath of Life programme addresses situations where the language hasn't been spoken for several generations but where there is documentary material, collected by linguists or anthropologists, which is housed in libraries and archives. Working together, language learners and scholars pair up with graduate linguistics students to locate relevant material and work on useful language resources, which can range from (re-)creating a prayer through to working on a spelling system for the language.

Because endangered languages are no longer widely spoken in everyday life, it can be difficult for learners to find people to converse with in their language. Many people in language revitalisation movements turn to activities such as songs, theatre and other performances in order to find ways to use and celebrate their language, as well as to create a sense of community endeavour (see Chapter 16 on arts and music). Or they may wear a T-shirt or jewelry with words in the language on, to demonstrate identity and solidarity. Performances and festivals are often very enjoyable occasions that bring together the community and raise awareness of the language and culture. A recent press release described how a school play was being performed entirely in Māori, a language which was banned in schools for over hundred years. The article mentions that not all of the performers are fluent in Māori, which could be interpreted negatively (they don't know the language properly), or positively (they are engaging with the language and trying to learn).

Another common focus of language activists is the 'linguistic landscape' - supporters campaign to have signage, public announcements, etc. in their language to raise its status, increase its presence in public life, and make non-speakers or tourists aware of it. If politicians or businesses support such measures, it is often in order to highlight local distinctiveness. These types of activities may not require fluency, but instead use parts of language symbolically or emblematically, to express identity. For many people this is a valid and adequate way of engaging with language, but it is only one way of looking at language revitalisation; for others, the aim may be to re-create a fluent speaker community, or to reclaim culture.

We are not suggesting that prioritising certain areas of language means that revitalisation should be one-dimensional; different registers and spaces of use can be complementary and mutually reinforcing, and individuals or groups may want to focus on different areas. It is important not to see these as mutually exclusive. There is a threat that if only a narrow spectrum of a given language is 'revitalised', the result may be perceived as artificial and not be sustainable. 
We argue that it is important to have conscious aims (see Chapter 4 on planning) and to be aware of the ideologies that underlie these aims, as well as different people's motivations for language-related activities (see the chapter on attitudes and ideologies). If not, we run the risk of losing a language through focusing only on symbolic activities. As Adrian Cain, Manx Language Development Officer, has commented: 'Language awareness raising isn't an end in itself, and if it doesn't encourage people to learn and speak, then it hasn't worked'.

\section{Who Is It For?}

In many situations, revitalisation efforts begin when there are still at least a few older speakers in the community, but they are initiated by younger generations. This leads to a paradox of language revitalisation: the momentum for revitalisation typically emerges from those who did not grow up as speakers of the language. The younger language activists, because they did not grow up with the language, are keenly aware of what they have not had access to in respect of their culture and identity (some learners of Guernesiais have said they felt 'robbed'). In the words of the Joni Mitchell song, 'you don't know what you've got 'til it's gone'. But to be able to revitalise the language, these 'new' speakers will want and need to involve older speakers. However, the needs and desires of these two groups of people may differ, and interactions can lead to some tricky social and political issues. One effective way of getting older and younger speakers together for mutual benefit is the Mentor-Apprentice model (also known as Master-Apprentice model), where an older or fluent speaker is paired with a person committed to learning and passing on the language (see Chapter 15 on teaching and learning for details).

As discussed in Chapter 8 on types of communities, in many endangered language communities there are a significant number of people who can understand the language but not speak it fluently. In Guernsey, an informal group who call themselves 'The Rememberers' (in Guernesiais, Les Rallumeurs or 're-kindlers') meet weekly to chat in Guernesiais and reactivate their passive language knowledge into active use, improving both fluency and accuracy - topics often include obscure words or grammatical points. The Rememberers are mainly aged 55-70 and some have not used Guernesiais for fifty years. In some cases, parents used Guernesiais with each other but not with the children, or in other cases Rememberers stopped speaking Guernesiais after discouragement at schools. The Rememberers is a rare example of effective bottom-up language planning which focuses on rebuilding social networks and increasing participants' frequency and fluency in everyday conversation and language use (rather than formal 
teaching). However, their conversations often focus on 'how the old people would have talked' rather than 'how we might talk in the future'. If this goes unnoticed, it might impact the ideas and possible choices about the kind of language that should be brought to the future, taught and revitalised. So even in an informal conversation group, it is important to think about our ideologies and goals of interaction, as well as which elements of language, such as topics, registers, and vocabulary, to focus on: for example, in one session a member of The Rememberers asked others to help recall or reconstruct words for movements such as leaning forward. (This is not to say that informal sessions should become formal grammar lessons, as seems to be happening in some Mentor-Apprentice programmes.)

\section{Language Change}

All living languages change over time, especially across generations. Languages also change due to the influence of other languages. Languages don't become endangered without another language that people are shifting to, and bilingual people always mix languages. We need to be aware of and accept the dynamic nature of language: the language we revitalise will not be the same as it was in the past, and that is completely normal. Some older speakers in Guernsey have expressed concern that if Guernesiais is taught in schools, 'it won't be the language we know'. They feel a strong connection to the language of their youth, and worry that it might become 'corrupted'. But if it is not taught to a new generation, it won't be a language that anyone knows. And that new generation needs to be able to pick it up and run with it, make it their own, and develop the language for whatever they want to use it for.

Change and growth are signs of life and health, not of decline. English, for example, has been enriched by many words from other languages: Wellknown examples include pyjamas from Hindi, robot from Polish or Czech, and chocolate from Nahuatl. Indeed, the only languages that don't change are truly dead languages, which may only exist in archives. Linguists have found that ironically, endangered languages change faster than larger or more vital languages. This is often due to influence from other languages, especially the dominant one(s), which can be difficult for some language supporters to accept, although it is impossible to prevent.

In the case of Māori and Guernesiais, practically all speakers have English as their dominant language, and most speakers under the age of around sixty are likely to have learnt Māori or Guernesiais as a second language (there are young neo-speakers of Māori, who have been brought up to speak it as a first language, but their parents are probably second language or 'new' speakers). As with all languages, we have observed 
differences in grammar and pronunciation between the speech of younger and older speakers (you can see this in English too, e.g. 'I'm like ...' instead of 'I said ...'.)

Linguists have observed that endangered languages undergoing change may seem to be simplified or to become more regular (e.g. in verb forms). But there can also be additions and new borrowed words or structures from a dominant language, especially given that people who are bilingual inevitably mix their languages (which is also frequently lamented, but can't be prevented). Sometimes direct translations can bring new and useful ways of saying things, such as bailler a hao in Guernesiais, a direct translation of English 'give up'. The pronunciation or accent of younger or new speakers may differ from that of older speakers, which again older speakers may find difficult to accept.

When the spaces where a language is used become restricted, its vocabulary and forms can also reduce, as some ways of using it become forgotten. When community members assimilate to a dominant culture and language, some of their cultural expressions may change or be lost, including traditional greetings, politeness and kinship terms, and counting systems. In the Isle of Man, a decision was taken to use the English number system rather than the traditional Manx one in the Manx-medium school, to enable the children to follow the mainstream curriculum.

We also find that highly endangered languages can fragment into many small varieties, which may be only used within one family or by one individual - all of whom may consider that they speak the correct way! These changes are often not new - for example, some can be seen in nineteenth century Guernesiais literature; in the Americas, such changes go back to the sixteenth century and are often well documented. But by the time they are noticed, it is not possible to stop them (if it were ever possible). It is important to stress that language change does not imply that our languages are inferior or unsuitable for use or for reinforcing. Neither should language change be seen as an obstacle to revitalisation.

\section{Purism}

An important part of language and cultural reclamation involves collecting and documenting the knowledge of elders and devising ways of expanding that knowledge. However, it is common to focus on the heritage aspects of the language, which link the language with the past. Even linguists are not immune to this, with one linguist recently confessing to not including borrowings from other languages when he documented a language in the 1970 s in a desire to represent only the 'purest' version of the language. 
The idea that there is an 'authentic' way of producing your language can lead to ideas that there is only one right way of speaking or writing. While it can be helpful to remember that all living languages change, it must be remembered that the sort of change a language undergoing revitalisation may experience can be extreme and challenging to older speakers.

One thing that hampers many revitalisation initiatives is language purism. 'Purism' is the idea that there is a 'pure' or 'real' or 'authentic' way of using your language. Typically, language purists are older speakers of a language who don't like the new pronunciations or simplified grammar used by 'new' speakers of a language (see Chapter 7 for more about language attitudes and ideologies). Along with this type of thinking comes the idea of ownership: There may be strong feelings about who owns the language and who gets to say what is right and what is wrong. There can also be new 'language owners' who stigmatise older speakers for using too many loanwords. In a revitalisation situation there are usually limited resources, so you need to include everybody who has an interest (see Chapter 10 for discussion of power dynamics).

It is worthwhile thinking about what 'authentic' really means: genuine, valid, real. If someone uses the language for a real purpose, whatever that use is, it is a valid, authentic reason for using language. For example, in Guernesiais there is a word, warro, which is used as informal greeting (like 'hello' or 'hi'). Although it has been documented as used by some of the oldest speakers and appears in a highly respected dictionary, the authenticity of this word has been called into question by some community members who say that it was not used in their families. ${ }^{1}$ But whether or not it was used in the past, people nowadays feel an authentic need for an informal greeting in Guernesiais. Using this word will encourage them to use Guernesiais more and facilitate real communication.

If your aim is to have the language spoken by younger generations, you need to be aware that the language will often need to change to be relevant to their interests and needs. All too often older speakers criticise younger ones, which can put them off speaking their languages entirely. It is more productive to encourage them to use the minority language, in whatever form it takes. It is known from research into language learning that there are intermediate stages before a learner acquires the whole of a new language. The processes of language contact and revitalisation can resemble some of the stages of language learning. In any kind of learning, we have to learn to walk before we can run; once new speakers become confident with what might be seen as 'simplified' language, they

${ }^{1}$ Fragmentation into small varieties, even between neighbouring families, is another common feature of highly endangered languages. 
can start to tackle more complicated traditional forms if they want to. It has to be remembered that young speakers are the future of any language. If it survives, it will belong to them.

\section{New Words for New Uses}

If your language hasn't been used as a community language for a while, it will need a big input of new vocabulary. Just think of all the technological words which have entered the major languages in just the last ten years: words for smartphone, app, to tweet, to unfriend. Not only might you need vocabulary for these concepts; if your language is to be used as a medium of instruction in schools, you will also need words for concepts such as graph, molecule, colonisation, and curriculum (see Chapter 15 on teaching and learning).

Simply borrowing words is often the easiest default option for new terms such as refrigerator. Some older speakers find it difficult to conceive of their language being used in new ways, and simply use the new language to describe new things. So their speech may be peppered with borrowed or loanwords, which some zealous new speakers may dislike. Some language planners (e.g. Irish) have been criticised for using mainly loanwords in nontraditional contexts, while others (e.g. Quechua) have been criticised for being too purist.

Languages have always had ways of creating new words, which can be studied and reproduced. If there are historical language records, traditional literature, accounts, poems, or documentary archives, one option is to rediscover, reintroduce, or repurpose some terms and structures that have fallen out of use. An example of this in English is the word broadcast, which originally meant to throw seed outwards in a field. It fell out of use with the mechanisation of farming, but was reintroduced as a metaphor when radio was invented. There are many additional ways of creating new terms in a language. In the late 1980s when revitalisation of the Māori language was well underway, the Māori Language Commission (Te Taura Whiri i te Reo Māori), in response to many community requests, coined a large number of new words using a variety of approaches. Their main aim was to avoid loanwords, so strategies included circumlocutions, for example, hekerangi to mean 'parachute' (literally heke 'to descend' and rangi 'sky'). Another frequent strategy was calquing, where the literal meaning of an English word was translated, for example, 'bisect' is weherua (wehe meaning 'to split' and rua meaning 'two'). Sometimes existing words were combined, for example pūhiko for 'battery', where $p \bar{u}$ means 'origin' and hiko means 'electricity'. In fact hiko originally meant 'lightning' and its meaning has been extended to include electricity. 
Another strategy was to repurpose archaic words (for example, ngota for 'atom' where the original meaning was 'fragment, particle').

In several languages, such as Manx and Māori, there are committees of people seen as language experts who are tasked with creating new words; but sometimes they take too long to decide on and disseminate new words. For example, teachers of Māori needed a word for 'number' to use in lessons and did not want to borrow a word. By the time the language committee had decided on a term, each teacher had their own different word.

Another way of developing new terminology is an inclusive 'crowdsourcing' approach, which encourages groups of people to talk about the topicboth face to face and online - and collect the most popular terms. This can even be done together with the oldest speakers to reduce possible tensions in the community about 'what to revitalise'.

\section{Not Just About Language}

Jeanette King's research has found that many people are not only (or principally) interested in revitalising a language for its own sake, but they often have a personal reason such as getting in touch with their family roots, joining a language community, or gaining a sense of achievement or wellbeing.

\section{Language, Culture, and Identity}

Language is deeply linked with culture. Most of those involved in language revitalisation talk about how culture is intrinsically linked to language. When you learn and speak a language you are learning and speaking culture. Some of this cultural expression may be in the form of cultural values, such as terms of address, etc. In addition, language can be closely related to cultural practices. For Māori in New Zealand, for example, the rituals of encounter in a powhiri (formal welcome) have to be delivered in Māori, with opening calls being performed by women, followed by speeches which necessarily contain much ritualistic language and expectations, such as paying respects to the dead. There is also the requirement for each speech to conclude with an appropriate song.

Most of those involved in language revitalisation are involved in reclaiming aspects of identity as well as cultural practices. This means that revitalisation is just as much about revitalising people as language. In other words, it's not just about what you are revitalising but who you are revitalising.

Language revitalisation often involves campaigning for someone else to do something, e.g. for a local government authority to erect signage, or for 
schools to teach the language. Such campaigns are valuable and can be a way for people who don't speak the language to get involved and to contribute to revitalisation. However, we need to be aware that it can be easier to focus on what others ought to do, rather than alter one's own behaviour, especially if one is not very confident in one's language competence. So, for example, some language promoters have reported that they find it easier to perform a poem or help in a classroom, which involves less impromptu language use than speaking it with their own children. So, increasing the self-confidence of language supporters is a vital part of language revitalisation.

\section{Conclusion}

Different people in language revitalisation movements have different aims and motivations. Some have a nostalgic, purist ideal of the kind of language they want to preserve. Others want to extend the areas where their language is used and have it recognised as a fully developed, modern language which can be used for all purposes. Others want to enjoy using their language with friends and family, while others want to affirm their identity through using a few words and phrases in greetings, rituals, songs, etc. Others may find that re-connecting with their language can enhance personal and community well-being.

All of these (and more) are valid elements of an overall language plan, but different priorities are too often a source of disagreement. It is therefore important to discuss openly what we want to achieve, why, and also what is achievable - in the short term, medium term, and long term. Plans should be regularly evaluated and revised, so that different functions, uses, and spaces can grow and be added to over time, as part of a longer sustainable plan. This involves recognising the strong feelings, attitudes, and ideologies that people have about language. Above all, it will involve compromise. These are all considerations when you are thinking about what sort of language you will be revitalising.

\section{FURTHER READING}

Aitchison, J. (2012). Language Change: Progress or Decay? 4th ed. Cambridge: Cambridge University Press.

Bentahila, A. and Davies, E. E. (1993). Language revival: Restoration or transformation? Journal of Multilingual and Multicultural Development 14, 355-74.

King, J. (2014). Revitalizing the Māori Language? In P. K. Austin and J. Sallabank, eds., Endangered Languages: Beliefs and Ideologies in Language Documentation and Revitalization. Oxford: Oxford University Press/British Academy, pp. 213-28. 
Romaine, S. (2006). Planning for the survival of linguistic diversity. Language Policy $5,441-73$.

Shandler, J. (2006). Adventures in Yiddishland: Postvernacular Language and Culture. Oakland, CA: University of California Press.

\subsection{Wymysiöeryś \\ Tymoteusz Król}

When I first started working on the revitalisation of Wymysiöeryś, I was focused on the language. The other elements of Wymysiöeryś culture seemed safer. I thought, for example, that you could collect traditional costumes and lock them in a wardrobe in a museum in order to preserve them. When we were children or teenagers, our task was to document everything that we understood as 'Wymysiöeryś': language, folk dress, recipes, old buildings, folk tales, etc. We were successful in doing this (we got a broad documentation), but mistaken in our approach (keeping it alive).

I realised our naivety as I started to write a dictionary of Wymysiöeryś. I had read all the dictionaries and grammars of Wymysiöeryś that I could find, but not a single one of these books described my language well enough to satisfy me. Later, I started to read poetry and saw that it only represented part of our language - the style is more literary and archaic than spoken usage. It was then that I realised that it is only by speaking a language can you keep it alive. It is the same in the case of Wymysiöeryś dress - when documented and closed behind glass in a museum these garments become dead artifacts of the past.

Documentation is essential: it is the basis of revitalisation but it is not the final goal. Also we have to take care of what we document. I often used to think about how I could create teaching materials using a 'pure' form of the language that was not Polonised or Germanised. But after a couple of years I stopped being so concerned with this - I gave up looking for 'the pure Wymysiöeryś language' and I started to listen to what people were actually saying (see Figure 2.1.1).

I noticed the same problem in the case of Wymysiöeryś costume. Elements of Wymysiöeryś folk dress used to be inspired by styles noticed or imported by Vilamovians living in Vienna, Paris, London, Graz, Lviv, and many other cities in Europe, and incorporated into local dress styles. Now many people bring folk costumes to Wymysoü from other cities as well, although these modern textiles and their patterns are very different from traditional local ones. Some anthropologists (and some Vilamovians as well) believe that this change is negative and that we cannot say that these new garments are truly 'Wymysiöeryś attire'. I agreed with them at first, but then I thought, 'who am I to judge'? Is the pattern on these new textiles more important than the fact that they were imported from the same cities as hundreds of years ago? Maybe the fact that they were imported from abroad is the most important tradition? In this way, I brought back textile designs and ideas from the ENGHUM field school in Mexico.

Judging these things as a scholar is, for me, a form of neocolonialism. An example of this is when Germanists argue about whether or not Slavic words, for 


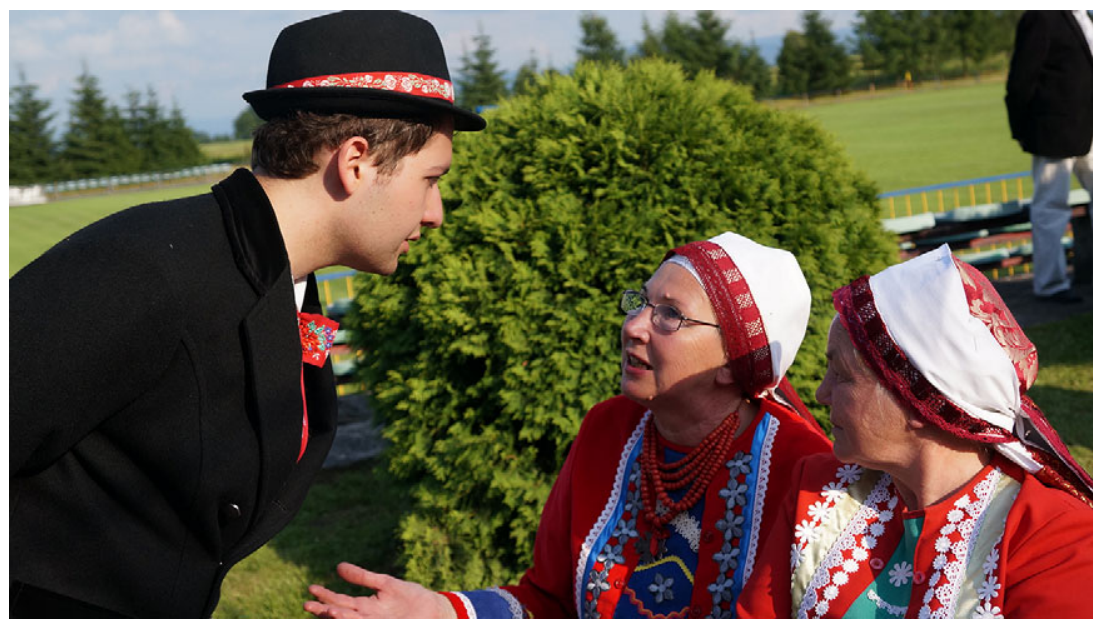

Figure 2.1.1 Speaking Wymysiöeryś: Tymoteusz Król, the revitaliser of the language. Photo by Justyna Olko

example, from Polish or the Silesian language, should be used in Wymysiöeryś, which is a Germanic language, or when linguists determine what is a language and what is a dialect.

I think that, as language activists and revitalisers, we can ask those linguists who decide that a language is in fact not a language, but 'only' a dialect: 'Who are you to judge a language in this way? Why are you able to reach this conclusion? What about the views of the people who speak it? Who are you to judge?'

\subsection{Language Purism in Nahua Communities}

\section{Justyna Olko}

Back in the 1970s, when Jane Hill and Kenneth Hill did extensive research in Nahua communities around the Volcano Malintzin in Tlaxcala, they discovered interesting facts about how Nahuatl was classified with regard to Spanish. ${ }^{2}$ Some speakers believed that what they called mexicano was an idioma ('language', always used in reference to Spanish), but most people identified Nahuatl as a 'dialect'. The reason given was it is mixed with Spanish, which results in tlahco mexicano, tlahco castellano, 'half Nahuatl, half Spanish', no longer having the legitimate status of a language in its own right. Today more people in Tlaxcala seem to identify Nahuatl as a 'language', which is probably a result of a more positive ideology arriving from the outside. However, in more secluded

2 J. Hill and K. Hill, Speaking Mexicano: The Dynamics of Syncretic Language in Central Mexico, 1st ed. (Tucson, AZ: University of Arizona Press, 1986). 
mountainous communities most of the speakers believe their tongue is a 'dialect', even if they cannot explain what a dialect is. And a clear majority is deeply convinced that mixing with Spanish is negative because 'Nahuatl is disappearing if it has Spanish words' and 'if people mix languages they no longer speak Nahuatl'. But at the same time, for this very reason, many speakers think their way of speaking is bad and very different than 'the legitimate Nahuatl' spoken once by their grandparents and great grandparents. In other words, they are often convinced that the jumbled (cuatrapeado) nature of the results of Nahuatl-Spanish contact is reflected in how they speak.

Accelerating language shift is accompanied by purist attitudes, which are often displayed most strongly by specific individuals or a particular group within a community. Such persons present themselves as 'owners' or 'guardians' of the heritage language, advising others which terms should be used and which must be avoided. They sometimes criticise both older speakers for their loanwords from Spanish, and the youngest speakers for their limited language skills and vocabulary. Purists would focus on eliminating all loanwords from Spanish (while inadvertently accepting direct translations!), including some words, which were incorporated into Nahuatl several hundred years ago. They also 'test' speakers on their knowledge of 'good' Nahuatl, for example asking them to say complex numbers (the traditional base-20 system has only partly survived and Spanish numerals are generally used). Degrees of purism are found not only among intellectuals and professional teachers, but also among community members.

Purist attitudes often have quite counterproductive effects on language survival. A good example is that of the community of Santa Ana Tlacotenco, where 'legitimate' Nahuatl has become a tool of internal politics. In the second half of the twentieth century this community suffered strong criticism of the locally spoken variant by members of academic circles who promoted the use of 'Classical' Nahuatl as the only legitimate version of the language. Today Nahuatl is spoken by very few people, most of them from the oldest generation. This decline in language use is accompanied by purist attitudes on the part of members of the middle-aged generation, but their approach hasn't been particularly helpful in keeping the language alive. Some activists, however, take a less restrictive approach, encouraging young people to explore the traditional vocabulary of the oldest generation rather than resort to substituting 'missing' words by borrowing from Spanish. They also engage in the creation of neologisms. Creating new words from within the language for new things has always been an important response of Nahuas to contact with Spanish, especially in the colonial period when the vitality of Nahuatl was high. This kind of purism can in fact stimulate the development of language skills and encourage speakers to explore and learn vocabulary and registers of the heritage language that have almost been forgotten or fallen out of use. 